\title{
Resilience as a predictor for emotional response to the diagnosis and surgery in breast cancer patients
}

Citation for published version (APA):

Markovitz, S. E., Schrooten, W., Arntz, A., \& Peters, M. L. (2015). Resilience as a predictor for emotional response to the diagnosis and surgery in breast cancer patients. Psycho-Oncology, 24(12), 1639-1645. https://doi.org/10.1002/pon.3834

Document status and date:

Published: 01/12/2015

DOI:

10.1002/pon.3834

Document Version:

Publisher's PDF, also known as Version of record

Document license:

Taverne

Please check the document version of this publication:

- A submitted manuscript is the version of the article upon submission and before peer-review. There can be important differences between the submitted version and the official published version of record.

People interested in the research are advised to contact the author for the final version of the publication, or visit the DOI to the publisher's website.

- The final author version and the galley proof are versions of the publication after peer review.

- The final published version features the final layout of the paper including the volume, issue and page numbers.

Link to publication

\footnotetext{
General rights rights.

- You may freely distribute the URL identifying the publication in the public portal. please follow below link for the End User Agreement:

www.umlib.nl/taverne-license

Take down policy

If you believe that this document breaches copyright please contact us at:

repository@maastrichtuniversity.nl

providing details and we will investigate your claim.
}

Copyright and moral rights for the publications made accessible in the public portal are retained by the authors and/or other copyright owners and it is a condition of accessing publications that users recognise and abide by the legal requirements associated with these

- Users may download and print one copy of any publication from the public portal for the purpose of private study or research.

- You may not further distribute the material or use it for any profit-making activity or commercial gain

If the publication is distributed under the terms of Article $25 \mathrm{fa}$ of the Dutch Copyright Act, indicated by the "Taverne" license above, 


\title{
Resilience as a predictor for emotional response to the diagnosis and surgery in breast cancer patients
}

\author{
Sabine E. Markovitz ${ }^{\text {* }}$, Ward Schrooten ${ }^{1,2}$, Arnoud Arntz ${ }^{3,4}$ and Madelon L. Peters ${ }^{3}$ \\ 'ZOL Ziekenhuizen Oost-Limburg, Genk, Belgium \\ ${ }^{2}$ Universiteit Hasselt, Diepenbeek, Belgium \\ ${ }^{3}$ Maastricht University, Maastricht, The Netherlands \\ ${ }^{4}$ University of Amsterdam, Amsterdam, The Netherlands
}

*Correspondence to:

ZOL Ziekenhuizen Oost-Limburg,

Genk, Belgium.

E-mail: Sabine.Markovitz@zol.be

Received: 29 August 2014

Revised: 21 March 2015

Accepted: 3 April 2015

\begin{abstract}
Objective: The purposes of the present study were to investigate the role of resilience in the prediction of emotional response in breast cancer patients and to examine whether this association is specific for women undergoing this emotionally taxing condition or whether resilience is more generally associated with higher levels of emotional well-being.

Methods: Two hundred fifty-three breast cancer patients and 211 healthy female controls completed four psychological questionnaires. Measures comprised the Connor-Davidson Resilience Scale, the Hospital Anxiety and Depression Scale, Positive and Negative Affect Schedule, and two happiness items. Cancer patients were assessed after diagnosis and surgery.

Results: Cancer patients reported higher levels of anxiety, depression, and negative affect and lower levels of positive affect and current happiness compared with control women. There was no difference between the two groups in level of resilience. Higher levels of resilience were related to better emotional adjustment both in women with breast cancer and in control women, but this association was stronger within the sample of cancer patients. In fact, patients scoring high on resilience seemed to experience similar levels of anxiety, depression, and current happiness as healthy women.

Conclusion: Our results confirm that resilience may at least partially protect against emotional distress in cancer patients. Our findings suggest that resilience may be a relatively stable trait that is not affected by adversity.

Copyright $@ 2015$ John Wiley \& Sons, Ltd.
\end{abstract}

\section{Background}

The diagnosis and treatment of cancer are considered to be emotionally disturbing or even traumatic $[1,2]$. The majority of cancer patients will at least experience elevated levels of emotional distress. A smaller group will develop significant long-term psychological problems in reaction to this potentially traumatic event [3-6].

Previous research has identified various moderating factors related to emotional response to the diagnosis of cancer. Demographic factors such as age, gender, and education and disease-related variables such as type of cancer, type of treatment, and stage of disease were found to be associated with different levels of emotional maladjustment [7]. Other studies found certain psychological (e.g., coping style) or environmental (e.g., social support) characteristics to be most influential in adapting to the emotional challenges of cancer $[6,8,9]$. The understanding of the emotional experience in cancer patients has long been framed in a deficit-centered approach with a focus on negative responses to cancer. With an increase of the overall survival ratio in cancer patients over the last decades, research shifted towards the emotional well-being of long-term cancer survivors [10,11]. These studies revealed that many patients remain psychologically healthy in spite of the multiple challenges of the disease.

Recently, interest has grown in identifying protective factors, enabling individuals to maintain emotional stability in times of adversity [12,13]. In search of a comprehensive psychological construct to explain the differences in the way individuals deal with stressful or traumatic events, the concept of resilience was introduced. Resilience has been defined as the dynamic capacity of an individual to maintain or regain mental health following exposure to stress or trauma [14]. Resilience can be seen as a set of characteristics such as self-efficacy, goal-orientation, adaptability to change, optimism, and the capacity to create secure attachments. Consensus exists regarding the fact that resilience can only be perceived and studied in the context of significant adversity. Nevertheless, there are discrepant views regarding the question whether resilience can be best conceptualized as a latent personality trait that becomes manifest during adversity or as a dynamic process that develops as a result of experiencing adversity [15]. 
The role of resilience in emotional adjustment has frequently been studied among individuals experiencing a significant traumatic event such as sexual or physical abuse, chronic disease, and environmental disasters [16-22]. Studies on resilience in cancer patients are, however, scarce and diffuse in scope. The few studies examining whether resilience can predict emotional adjustment after cancer diagnosis found resilience to be related to higher quality of life, lower emotional distress, and less fatigue in cancer patients and survivors [23-25]. Two limitations apply to the majority of these resilience studies: the lack of a control group and/or small sample sizes. To be able to draw conclusions regarding the specific dynamics of resilience in cancer patients, a control group is mandatory.

Other studies have examined whether the diagnosis of cancer itself can impact on an individual's level of resilience and found that cancer survivors appear to be more resilient than people not suffering from cancer [26-28]. These results suggest that resilience may be triggered by adversity. However, there is no general consensus whether resilience is a trait or a state triggered by stressful or traumatic events, and further research is needed.

The aim of the present study was (a) to investigate the role of resilience in the emotional response to the diagnosis and surgery in cancer patients and (b) to compare the level of resilience of cancer patients to that of individuals not suffering from cancer and, by implication, to gain insight whether resilience is a stable trait or a state triggered by adversity.

We hypothesize that high resilience protects against negative emotional impact (i.e., lower depression and anxiety, less negative affect, higher positive affect, and higher happiness). If resilience is indeed a factor that buffers the negative impact of adversity, it should have a stronger association with emotional response in women with breast cancer.

\section{Methods}

\section{Participants}

Between 2009 and 2013, 284 women diagnosed with primary breast cancer were recruited consecutively at time of hospitalization for breast surgery in a hospital in the province of Limburg, Belgium. All subjects received the diagnosis of breast cancer between 1 and 2 weeks before admission to the hospital. Subjects were eligible for inclusion if they were between 20 and 80 years old, were residents in the province of Limburg, had sufficient cognitive ability, and had mastered the Dutch language. All participating patients were diagnosed with primary breast cancer stage I or II and underwent lumpectomy or mastectomy with or without immediate breast reconstruction.

Informed consent was obtained from 284 patients; 31 of these did not return the questionnaires (12\%), leaving a total of 253 patients for analyses. All patients completed the questionnaires after undergoing surgery but before dismissal from the hospital. Reasons for not returning the questionnaires were 'forgotten', 'lost', or 'too confronting'.

To examine whether the associations between resilience and emotional reactions are specific for women undergoing an emotionally taxing condition like being diagnosed with breast cancer or whether resilience is more generally associated with higher levels of well-being and healthy emotional functioning, a control group of women not having been diagnosed with breast cancer was included. Therefore, 211 control subjects were recruited in a provincial Woman's association $(N=105)$ and among our female hospital staff ( $N=21$ administrative and $N=85$ medical). Except for the diagnosis of cancer, inclusion criteria were identical as for the clinical group.

\section{Measurements}

Psychological resilience was measured with the 25-item Connor-Davidson Resilience Scale, an instrument with proven good psychometric qualities [29]. Cronbach's alpha in the present study was 0.89 . The 25 items are rated using a 5-point Likert scale. Sample items are 'Able to adapt to change', 'Can deal with whatever comes', and 'Coping with stress strengthens'. Higher scores indicate higher degrees of resilience. It is recommended by the authors to use this instrument as a unifactorial scale.

To assess depressive and anxiety symptoms, we used the Hospital Anxiety and Depression Scale [30]. Seven items assess depression, and another seven anxiety. Cronbach's alpha for the depression and anxiety scales were 0.81 and 0.80 , respectively, in the present study. The items are rated using a 4-point Likert scale. Higher scores reflect higher levels of depression and anxiety.

To measure affect, we used the shortened version of the Positive and Negative Affect Schedule [31]. Items represent five positive and five negative emotions and are rated on a 5-point scale. Cronbach's alpha for the positive and negative affect subscales were respectively 0.89 and 0.85 in the present study.

To measure happiness, we used two single-item questions [32]. The item 'Considering your life in general, how happy would you describe yourself?' assessed general happiness. Current happiness was measured with the item 'How happy would you describe yourself at this moment'. Both items were rated on a scale ranging from 1 to 7 . Measuring happiness by single-item questions has been proven to be reliable and valid [33]. The correlation between general and current happiness in our study was 0.31 in the total group.

We controlled for negative life events during the last year in both groups with the life events scale [34]. There was no significant difference between the groups regarding number of negative life events. 


\section{Procedures}

During the hospital admission procedure, the breast cancer nurse asked consecutive breast cancer patients to participate in this study. After obtaining informed consent, participants completed the four self-rating questionnaires after surgery and before dismissal from the hospital. Patients also provided information concerning age, educational level, and marital status. Medical data were collected during the weekly multidisciplinary meeting where all medical disciplines provide information concerning the site and type of the tumor, the type of primary treatment (surgery), and the type of secondary treatments (no treatment, hormonal therapy, radiation therapy, and chemotherapy).

Local representatives from the Woman's Association recruited participants for the control group through announcements. Hospital staff members were recruited through email. Control participants received the questionnaires at their home address and returned them using a prepaid envelope. The ethical committee of the hospital approved the procedure.

\section{Statistical analysis}

Analyses were conducted using SPSS version 19.

The sociodemographic and psychological characteristics of the control and cancer patient groups were compared using $t$-tests and chi-squared tests. Multivariable linear regression analyses were performed to examine the influences of resilience and group on emotional adjustment, after adjusting for covariates. Resilience, group, and the interaction term 'resilience $\mathrm{x}$ group' were entered as predictor variables. The interaction terms were based on centered variables. The interaction resilience $\mathrm{x}$ group indicates whether the association between resilience and emotional response differs between patients with breast cancer and control women. A main effect of resilience (with a non-significant interaction term) indicates that higher levels of resilience are equally beneficial for cancer patients and control participant. Separate analyses were performed for the dependent variables general and current happiness, positive and negative affect, depression, and anxiety. Covariates included significantly different demographic variables (age and educational level) between the control and clinical groups. Dummy coding was used for the group variable $(0=$ control group and $1=$ breast cancer patients), and linear coding was used for educational level $(1=$ low, $2=$ intermediate, and $3=$ high $)$. In case of a significant resilience $\mathrm{x}$ group interaction term, $t$-tests comparing the groups at -2 standard deviation (SD), mean, and +2 SD levels of resilience were executed with the generalized linear mixed models module of SPSS, which gives the opportunity to do $t$-tests at specific levels of the covariate. The other covariates were set at their mean level. When the interaction term is proved non-significant, it was removed in order to be able to interpret the main effect.

\section{Results}

A total of 464 participants ( 253 breast cancer patients and 211 control subjects) were enrolled in the study. As shown in Table 1, the groups differed significantly in age and educational level, but not in marital status.

Cancer patients had significant higher scores on anxiety, depression, and negative affect and lower scores on positive affect and current happiness. General happiness was significantly higher in cancer patients than in control participants. In fact, patients scored on average higher than the norm for general happiness in the Belgian population, which is $5.2(\mathrm{SD}=0.9)$ [32]. The level of resilience did not differ between the groups.

Table 2 shows the results of the multivariable linear regression analyses. Age and education were not significantly related to current happiness, depression, anxiety, or positive affect. However, age was significantly negatively associated with happiness in general and negative affect.

The interaction term resilience $\mathrm{x}$ group has reached significance for most of the outcome variables, except for positive affect (and borderline significance for general happiness). Figure 1a-d illustrates the effects for the four outcome variables for which the interaction term reached significance. It shows the scores on current happiness, negative affect, anxiety, and depression for patients and

Table I. Demographic, predictor, and dependent variables

\begin{tabular}{|c|c|c|c|}
\hline Variable & $\begin{array}{c}\text { Breast cancer } \\
\text { patient }\end{array}$ & $\begin{array}{l}\text { Control } \\
\text { group }\end{array}$ & $\begin{array}{c}\text { Statistical } \\
\text { comparison } \\
(p)^{\mathrm{a}}\end{array}$ \\
\hline Age (years, mean, SD) & $53.9 \pm 10.5$ & $45.7 \pm 12.3$ & $<0.001$ \\
\hline Education, no. (\%) & & & $<0.001$ \\
\hline Low (6 years) & $54 / 253(21.3)$ & $16 / 21 \mid(7.5 \%)$ & \\
\hline $\begin{array}{l}\text { Intermediate } \\
\text { (12 years) }\end{array}$ & $96 / 253(37.9)$ & $53 / 211(25.1 \%)$ & \\
\hline High (>12 years) & $99 / 253(39.1)$ & $|42 / 2| \mid(67.2 \%)$ & \\
\hline Marital status, no. (\%) & & & 0.514 \\
\hline Married/living together & 202/253 (80) & $|72 / 21|(81)$ & \\
\hline Divorced & $20 / 253(8)$ & $|8 / 21|(8.5)$ & \\
\hline Widow & I5/253 (5.9\%) & $6 / 211(2.8)$ & \\
\hline Single & $12 / 253$ & $15 / 21 \mid(7.1)$ & \\
\hline \multicolumn{4}{|l|}{$\begin{array}{l}\text { Psychological Measures } \\
\text { (mean, SD) }\end{array}$} \\
\hline CD-Risc & $93.8 \pm 14.6$ & $93 \pm 11.9$ & 0.534 \\
\hline $\begin{array}{l}\text { Happiness I } \\
\text { (life in general) }\end{array}$ & $5.5 \pm 0.9$ & $5.3 \pm 0.7$ & 0.007 \\
\hline $\begin{array}{l}\text { Happiness } 2 \\
\text { (at this moment) }\end{array}$ & $4.5 \pm 1.2$ & $5.3 \pm 0.9$ & $<0.001$ \\
\hline HADS anxiety & $12.1 \pm 4.3$ & $10.3 \pm 3.5$ & $<0.001$ \\
\hline HADS depression & $9.4 \pm 4$ & $8.1 \pm 2.8$ & 0.001 \\
\hline PANAS positive affect & $12.9 \pm 4.7$ & $19.9 \pm 3.3$ & $<0.00$ । \\
\hline PANAS negative affect & $|4| \pm 6.4$. & $9.4 \pm 4$ & $<0.001$ \\
\hline
\end{tabular}

SD, standard deviation; CD-Risc, Connor-Davidson resilience scale; HADS, Hospital Anxiety and Depression Scale; PANAS, Positive and Negative Affect Schedule. ${ }^{\mathrm{a} C h i-s q u a r e d ~ t e s t ~ a n d ~} t$-test. 
Table 2. Multivariate linear regression results for happiness, HADS, and PANAS

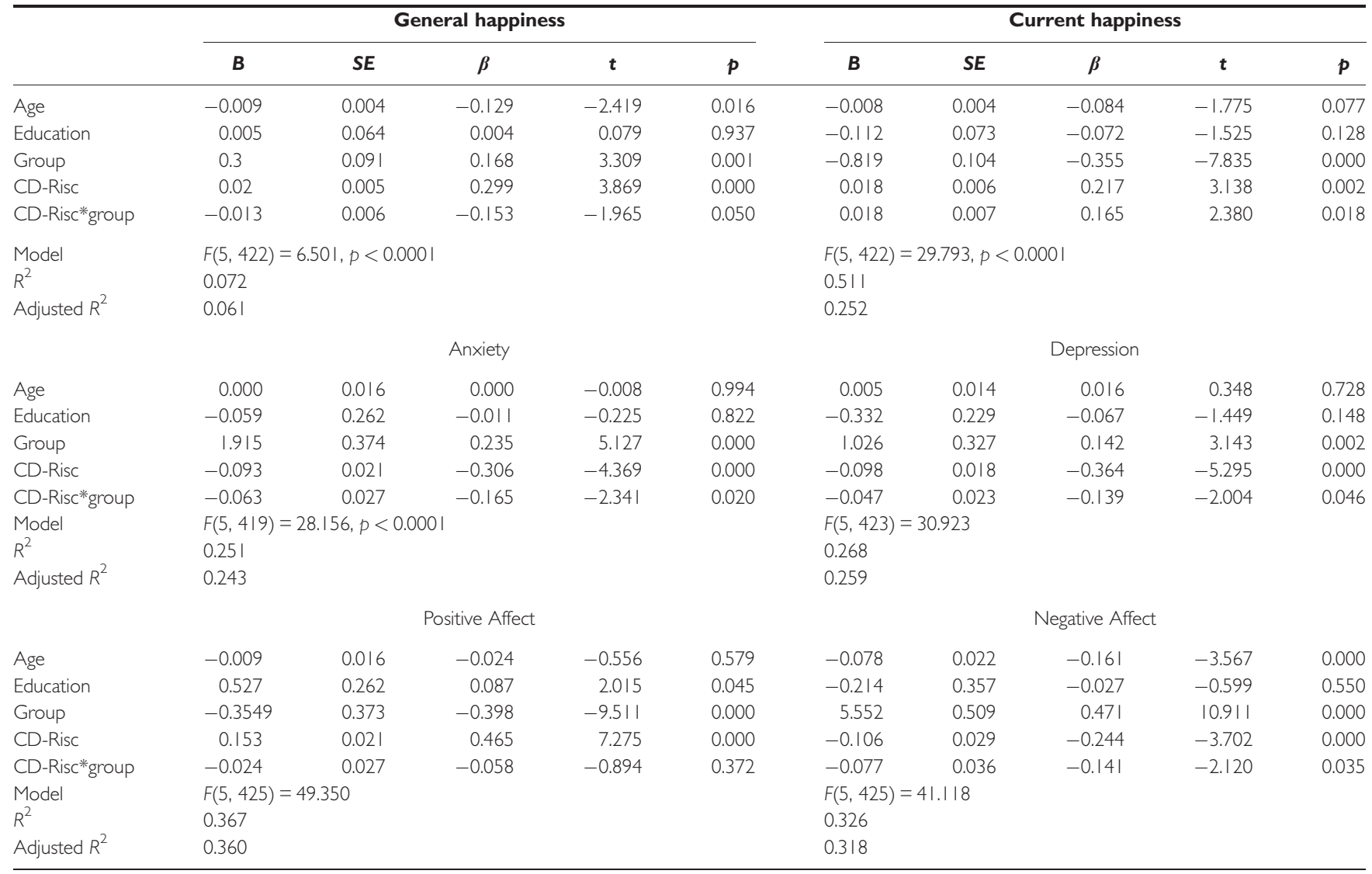

$B$, parameter estimate; SE, standard error; $\beta$, standardized coefficient; CD-Risc: Connor-Davidson resilience scale.

controls with respectively low $(-2 \mathrm{SD})$, medium, and high (+2SD) scores on resilience. Higher scores denote higher levels of the emotional variable. Whereas cancer patients with low to moderate levels of resilience report more anxiety, more depression, and less current happiness than women without cancer, patients with higher resilience show similar scores to control participants on these variables. $t$-Tests confirmed that highly resilient cancer patients did not differ significantly in anxiety $(t(416)=0.32$, $p=0.74)$, depression $(t(420)=-0.34, \quad p=0.73)$, and current happiness $(t(422)=-1.51, p=0.13)$ from control participants. At low and mean levels of resilience, patients reported significantly more anxiety (respectively, $t(416)$ $=4.33, p<0.001$ and $t(416)=5.12, p<0.001)$, depression (respectively, $t(420)=3.16, p<0.05$ and $t(420)=3.1$, $p<0.05$ ), and current happiness (respectively, $t(422)=$ $-5.66, p<0.001$ and $t(422)=-7.84, p<0.001)$ than controls.

Even though the interaction effect also reached significance for negative affect, cancer patients reported higher negative affect at all levels of resilience. At low, mean, and high resilience, the difference between the groups reached significance (respectively, $t(421)=6.96, p<0.001$, $t(421)=11.16, p<0.001$, and $t(421)=3.280, p=0.001)$. Nevertheless, the difference between the groups was smallest for high resilience and gradually increased when resilience was smaller.

For general happiness, the resilience $\mathrm{x}$ group interaction was borderline significant $(p=0.05)$. After removal of this interaction term, the effects of resilience $(\beta=0.179$, $p<0.001)$, group $(\beta=0.166, p<0.001)$, and age $(\beta=$ $-0.129, p=0.016$ ) were significant. Cancer patients report higher general happiness, regardless of their level of resilience. In the control group, similar levels of happiness are only reached in individuals with high resilience. $t$-Tests confirmed that high-resilient cancer patients did not differ significantly from high-resilient controls $(t(422)=-0.22$, $p=0.826$ ). Cancer patients with low or mean levels of resilience report a significantly higher level of general happiness than healthy women (respectively, $t(422)=3.32, p=0.001$ and $t(422)=3.31, p=0.001)$.

For positive affect, the resilience $\mathrm{x}$ group interaction was not significant. After deletion of this interaction term, the effects of group $(\beta=-0.398, p<0.001)$ and resilience $(\beta=0,179, p<0.001)$ were significant. There was an overall association between higher resilience and higher positive affect, which was in contrast to the other outcome variables, not stronger in the patient group. Patients with cancer report lower positive affect than control women, even at high levels of resilience. 

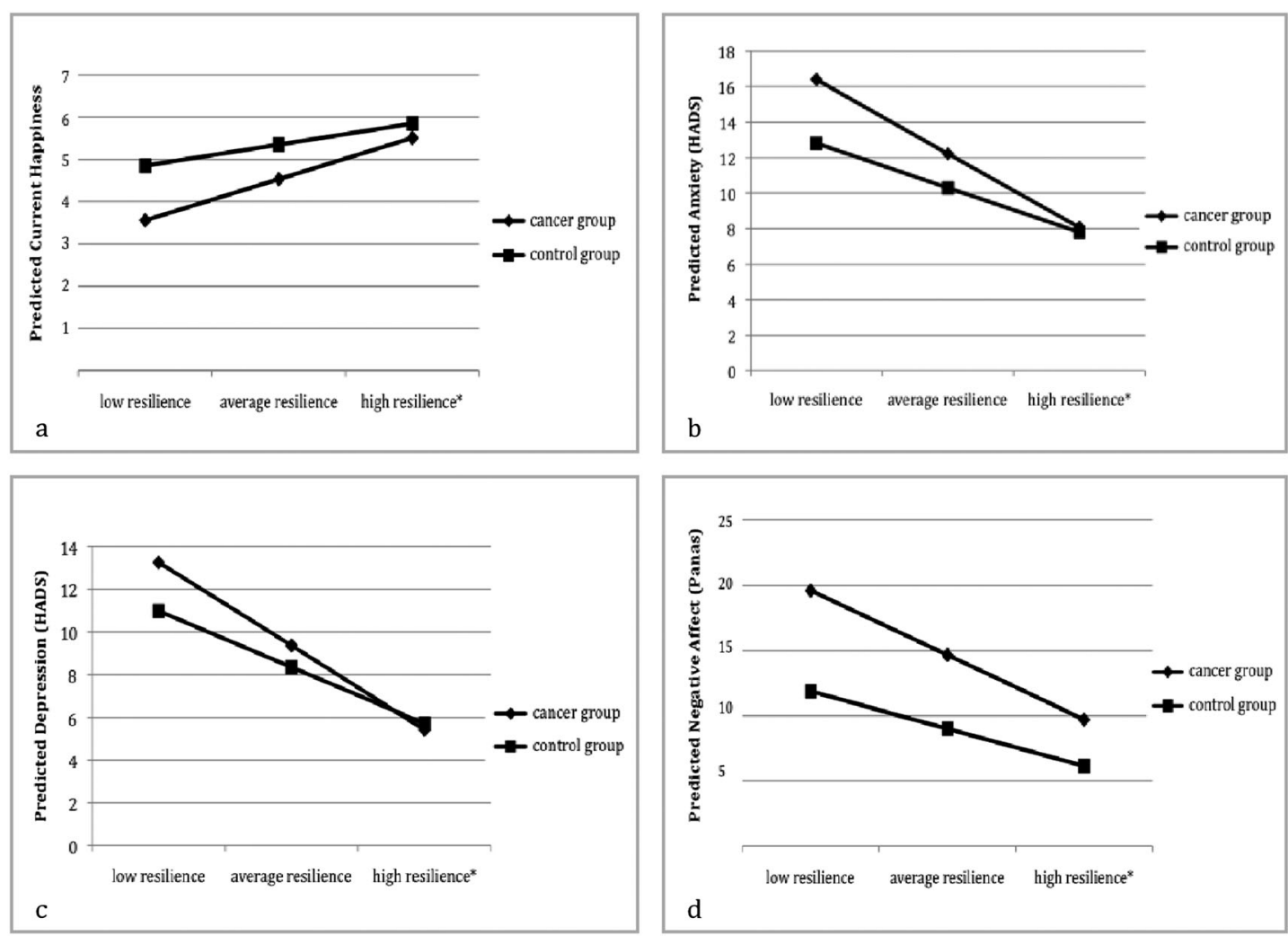

Figure I. Illustration of the resilience $x$ group interaction effects for (a) current happiness; (b) anxiety; (c) depression and (d) negative affect. Scores on the respective outcome variables for individuals with low $(-2 S D)$, mean and high (+2SD) levels of resilience in both groups are displayed

$t$-Tests confirmed that at low, mean, and high levels of resilience, controls report significantly higher positive affect than cancer patients (respectively, $t(421)=-3.37$, $p=0.001, t(421)=-9.5, p<0.001$, and $t(421)=-5.4$, $p<0.001)$.

Finally, within group regressions showed that the resilience effects reached significance for all outcome variables both in cancer patients and control women, except for general happiness in cancer patients.

\section{Discussion}

The main findings of this study can be summarized as follows. Levels of resilience were similar in both groups. As a group, cancer patients reported more depression, anxiety, negative affect, and less current happiness. However, patients with high levels of resilience reported similar levels of emotional well-being as women in the control group, with the exception of positive and negative affect.

Our findings confirmed that cancer can have a major impact, as illustrated by the elevated scores on anxiety, depression, negative affect, and less feelings of happiness. However, this study aimed to go beyond a problemcentered perspective. In search of protective factors associated with lower emotional distress, we established that a diagnosis of cancer does not lead to emotional disturbance among all patients. We found higher levels of resilience to have a protective impact. In particular, we established that resilience protects cancer patients against the development of psychological symptoms such as depression and anxiety. Further, high resilience enables individuals to maintain a high level of current happiness, despite adversity. However, our findings reveal that high resilience does not play a substantial role in decreasing negative emotions in cancer patients, nor in keeping positive emotions on a normative level. These findings support the idea that high-resilient individuals obviously experience negative emotions while being confronted with a stressful event, but that they possess characteristics that make them better equipped to deal with these negative emotions and distress, which eventually prevent them from developing psychopathology [35,36].

These results are consistent with the original conceptualization of resilience as proposed by Rutter [14]: people with high resilience are not immune to emotional distress, but they manage to maintain emotional stability despite this intrinsically negative experience.

The findings also support our second prediction that the association between resilience and emotional well-being is stronger for cancer patients than for control participants. Our results favor a protective model of resilience on pathological effects of emotional distress. 
Our results did not support previous evidence [27] that cancer patients have higher levels of resilience compared with individuals without cancer. This finding suggests that resilience may be a relatively stable trait rather than a state triggered by a stressful event.

Noteworthy is the fact that cancer patients with high scores on resilience do not just have 'less' symptoms of anxiety, depression, and higher feelings of current happiness; they have similar levels on these variables as control women with high resilience, and even more favorable levels than low resilient control women.

Cancer patients report higher feelings of general happiness. A possible explanation for this result is the wellknown effect of response shift in quality of life studies. Cancer patients may overestimate their previous feelings of happiness in the recent context of adversity. This is consistent with the finding that cancer patients score on average higher than the norm score for the Belgian population [32]. The meaning of happiness may be shifted [37].

These results support and extend the previous findings on this topic [25] and indicate that the relationship between resilience and emotional adjustment is substantial. By including a control group, we were able to compare how resilience relates to emotional functioning in general and in the context of adversity. Adversity did not seem to have an impact on the level of resilience, but we found resilience to be a crucial contributor to the emotional response after adversity. We established this significant impact of resilience in all individuals; however, this relationship appeared to be stronger in cancer patients. This finding implies that high resilient individuals are better equipped to maintain good psychological functioning while facing adversity.

The identification of resilience as a protective factor against developing psychopathological symptoms after cancer diagnosis can be useful in a clinical setting. Screening for resilience among cancer patients can lead to early detection and selection of patients with lower resilience and a potentially higher vulnerability to develop emotional problems. For those patients, resilience-enhancing interventions to prevent the development of psychopathology may be desirable.

\section{References}

1. Jim HS, Jacobsen PB. Posttraumatic stress and posttraumatic growth in cancer survivorship: a review. Cancer $J$ 2008;14(6): 414-419.

2. Koutrouli N, Anagnostopoulos F, Potamianos G. Posttraumatic stress disorder and posttraumatic growth in breast cancer patients: a systematic review. Women Health 2012;52(5):503-516.

3. Jarrett N, Scott I, Addington-Hall J et al. Informing future research priorities into the psychological and social problems faced by cancer survivors: a rapid review and
This study has several limitations. First, it is based on self-reports and relies on the validity of self-report instruments. In further research, inclusion of interviews or backup information from important others is desirable. Second, this study is conducted in an entirely female sample. To date, there are mixed findings about gender differences in resilience or in impact of resilience on emotional functioning. Some studies found that women are more resilient, whereas others have revealed that men are more resilient, and some studies established no difference $[38,39]$. To allow generalization of these findings, the inclusion of male cancer patients and controls is necessary. Third, there were differences in age and education between the groups. Although we controlled for that statistically, future studies could make use of matched samples. Also, as assessment was held shortly after diagnosis, the emotional response may be underestimated because of feelings of shock and denial or because patients are required to make a number of treatment-related decisions in a short amount of time. Finally, conclusions about the protective function of resilience should be interpreted with caution, given the cross-sectional nature of this study. These conclusions need to be confirmed with a longitudinal design.

To summarize, we confirmed that cancer patients are emotionally challenged. Additionally, we established that resilience appears to be an essential contributing factor in emotional functioning: patients with a higher level of resilience are not protected against the emotional impact of the diagnosis of cancer, but they may be better equipped to withstand the potentially negative impact on current happiness, and they are less likely to respond with depressive or anxious symptoms.

Finally, we have found that cancer patients did not differ from the control group in terms of level of resilience. It appears that being confronted with adversity does not have an impact on resilience. This finding may contribute to the ongoing discussion whether resilience is a state or an individual trait [40]. Longitudinal research assessing resilience and emotional adjustment at various time points in the months following diagnoses is appropriate to clarify the role of resilience. synthesis of the literature. Eur J Oncol Nurs 2013;17(5):510-520.

4. Mitchell AJ, Chan M, Bhatt $\mathrm{H}$ et al. Prevalence of depression, anxiety and adjustment disorder in oncological hematological and palliative-care settings: a meta-analysis of 94 interview-based studies. Lancet Oncol 2011;12:160-174.

5. Stein KD, Syrjala KL, Andrykowski MA. Physical and psychological long-term and late effects of cancer. Cancer 2008;112(11):2577-2592.

6. Kangas M, Henry JL, Bryant RA. Predictors of posttraumatic stress disorder following cancer. Health Psychol 2005;24(6):579-585.
7. Helgeson VS, Snyder P, Seltman H. Psychological and physical adjustment to breast cancer over 4 years: identifying distinct trajectories of change. Health Psychol 2004;23(1):3-15.

8. Stanton A, Danoff-Burg S, Cameron CL et al. Emotionally expressive coping predicts psychological and physical adjustment to breast cancer. J Consult Clin Psychol 2000;68(5): 875-882.

9. Epping-Jordan JE, Compas BE, Osowiecki DM et al. Psychological adjustment in breast cancer: processes of emotional distress. Health Psychol 1999;18(4):315-326. 
10. Woodgate RL. Conceptual understanding of resilience in the adolescent with cancer: part 1. J Pediatr Oncol Nurs 1999;16(1):35-43.

11. Aspinwall LG, MacNamara A. Taking positive changes seriously: toward a positive psychology of cancer survivorship and resilience. Canc Suppl 2005;104(11): 2549-2556.

12. Aspinwall LG, Staudinger UM (Eds). A Psychology of Human Strengths: Fundamental Questions and Future Directions for a Positive Psychology, APA Books: Washington, DC, 2003.

13. Seligman MEP, Csikszentmihalyi M. Positive psychology: an introduction. Am Psychol 2000;55:5-14.

14. Rutter M. Resilience: some conceptual considerations. J Adolesc Health 1993;14: 626-631.

15. Luthar SS, Cicchetti D, Becker B. The construct of resilience: a critical evaluation and guidelines for future work. Child Dev 2000;71(3):543-562.

16. Bonanno GA. Loss, trauma and human resilience: have we underestimated the human capacity to thrive after extremely aversive events? Am Psychol 2004;59(1):20-28.

17. Bonanno GA, Galea S, Bucciareli A, Vlahov D. What predicts psychological resilience after disaster? The role of demographics, resources, and life stress. $J$ Consult Clin Psychol 2007;75(5):671-682.

18. Howard S, Dryden J, Johnson B. Childhood resilience: review and critique of literature. Oxf Rev Educ 1999;25(3):307-323.

19. Karoly P, Ruehlman LS. Psychological resilience and its correlates in chronic pain: findings from a national community sample. Pain 2006;123:90-97.

20. Lyons J. Strategies for assessing the potential for positive adjustment following trauma. $J$ Trauma Stress 1991;4:93-111.
21. Stewart DE, Yuen T. A systematic review of resilience in the physically ill. Psychosomatics 2001;52:199-209.

22. Tucker PM, Pfefferbaum B, North CS, Kent A, Burgin CE, Parker DE. Physiologic reactivity despite emotional resilience several years after direct exposure to terrorism. Am $J$ Psychiatr 2007;164:230-235.

23. Tartaro J, Roberts J, Nosarti C. Who benefits? Distress, adjustment and benefit-finding among breast cancer survivors. $J$ Psychosoc Oncol 2005;23:45-64.

24. Strauss B, Brix C, Fischer S et al. The influence of resilience on fatigue in cancer patients undergoing radiation therapy. J Canc Res Clin Oncol 2007;133:511-518.

25. Min Y, Yoon S, Lee C et al. Psychological resilience contributes to low emotional distress in cancer patients. Support Care Cancer 2013;21:2469-2476.

26. Wenzel LB, Donelly JP, Fowler JM. Resilience, reflection and residual stress in ovarian cancer survivorship: a gynecologic oncology group study. Psycho-Oncology 2002;11:142-153.

27. Gotay CC, Isaacs P, Pagano I. Quality of life in patients who survive a dire prognosis compared to control cancer survivors. PsychoOncology 2004;13:882-892.

28. Costanzo ES, Ryff CD, Singer BH. Psychosocial adjustment among cancer survivors: findings from a national survey of health and wellbeing. Health Psychol 2009;28:147-156.

29. Connor KM, Davidson JRT. Development of a new resilience scale: the Connor-Davidson Resilience Scale (CD-RISC). Depress Anxiety 2003;18:76-82.

30. Zigmond AS, Snaith RP. The Hospital Anxiety and Depression Scale. Acta Psychiatr Scand 1983;67(6):361-370.

31. Mackinnon A, Jorm AF, Christensen H, Korten AE, Jacomb PA, Rodgers B. A short form of the Positive and Negative Affect Schedule: evaluation of factorial validity and invariance across demographic variable in a community sample. Pers Indiv Differ 1999;27:405-416.

32. Veenhoven R. Happiness in nations. World Database of Happiness, Erasmus University Rotterdam, The Netherlands, 2008. (Available from: http://worlddatabaseofhappiness.eur.nl/ hap_nat/nat_fp.php?mode=1).

33. Abdel-Khalek A. Measuring happiness with a single-item scale. Soc Behav Pers 2006;34(2): 139-150.

34. Garnefski N, Kraaij V, Spinhoven P. Negative life events, cognitive emotion regulation and emotional problems. Pers Indiv Differ 2001;30:1311-1327.

35. Hjemdal O, Friborg O, Stiles TC, Rosenvinge $\mathrm{JH}$, Martinussen M. Resilience predicting psychiatric symptoms: a prospective study of protective factors and their role in adjustment to stressful life events. Clin Psychol Psychother 2006;13:194-201.

36. Ong AD, Bergeman CS, Bisconti TL, Wallace KA. Psychological resilience, positive emotions and successful adaptation to stress in later life. J Pers Soc Psychol 2006;91(4): 730-749.

37. Schwartz CE, Sprangers MAG. Adaptation to changing health: response shift in quality-of-life research. Washington DC, US American Psychological Association, 2000; 73-77.

38. Campbell-Sills L, Forde DR, Stein MB. Demographic and childhood environmental predictors of resilience in a community sample. J Psychiatr Res 2009;43:1007-1012.

39. Morano C. Resilience and coping with trauma: does gender make a difference? J Hum Behav Soc Environ 2010;20(4):553-568.

40. Jacelon CS. The trait and process of resilience. $J$ Adv Nurs 1997;25(1):123-129. 